\title{
Editorial
}

\section{Developing a Practical Approach to Change}

Forecasting and attempts to predict what will happen is an innate aspect of the human condition that transcends the walls of the organizations in which we work or the careers that we have chosen. As academic libraries enter into the $4^{\text {th }}$ (or $\left.5^{\text {th }}\right)$ Industrial Revolution, we are awash in trends, futurists, analysts, reports, innovations, bold initiatives and a plethora of people attempting to get many of us into the headspace of what will and can happen rather than the mundanities of the present. While I am glad that the trend of asking about the $21^{\text {st }}$ century library is waning now that we are $20 \%$ of the way into it, I am also in a new position of administrative responsibility and authority in which I am quite lost as to how to find a direction and help steer the organization within the current environment. I do not believe that I am alone in the struggle of figuring out trends, but I find that I am in a bit of an existential crisis in trying to determine what to do next. The promise of Plan $S$ and a wonderful future of openly accessible content is not enough to sustain me into the near or distant future without thinking about a pragmatic approach to the constant winds of change. I feel that much practicality and pragmatism is getting lost in our continued chase after the 'next big thing.' It is important that our visionaries and idea generators connect with the people who can make sure that ideas are actually implemented and usable to our changing constituencies. I believe that this connection, however, is tenuous and the strengths and skills that many of us already possess are often lost or not applied practically to the various changes upon which we are embarking.

In my first year, I have already written documents on behalf of our library for various administrative and non-librarian audiences. They include all the current buzzwords because we are wrestling with how to engage in new ways with our existing community, new users, and collaborators in ways that haven't even been defined. When faced with a string of world salad statements and interests, how does this translate into something positive and achievable? My own approach is to keep things simple and discuss the future and how to take a pragmatic and practical approach, especially as it relates to public services or operations. My practical advice for dealing with change is to:

- Plan for the worst

- Hope for the best

- Be opportunistic

I believe that this philosophy will stand in good stead for developing a useful and practical skillset for dealing with the miasma of change and uncertainty - be it in our libraries, academic institutions or beyond. In planning for the worst, we need to hone our ability to forecast and have a basic understanding of the future and the possibilities. It is, essentially, risk analysis. This kind of planning encourages structured discussions about all of the things that could happen and how to make decisions about their likelihood, how bad they truly may be, and if there is a way to spin it strategically so that an opportunity can be found within this kind of change. 
While librarians are fantastic at going down the 'what if' path, this exercise is for planning and contingencies, not for finding a way to not do something.

Hoping for the best is essentially finding the positive approach to all the uncertainty. Looking for the positive and hopeful outcomes of change and future possibilities allows for the ability to sow the seeds of opportunity. The outlook we possess is one of the best assets for dealing with a plethora of multiple futures. We all possess the ability to inspire others and be the leaders of change when articulating the hopeful possibilities of various initiatives. This mindset also sets the table for being able to dictate and, hopefully, control one's future when opportunities arise rather than feeling forced through those changes. Opportunities do not line up often, so when they do, our planning and hoping will put us in a good place to take advantage of those situations, make significant progress, and move the needle forward for as long as possible.

Academic libraries and the communities that they serve are facing change. Some of it is iterative, some of it transformational, some of it... catastrophic. Depending on our mental fortitude and personal capacity for change, even the lightest touch can cause high stress. We employ many methods and modes of coping with this, but it does not give a practical approach to working through the change and seeing yourself and your responsibilities at the end of the process. For many change management professionals, the focus is on the individuals involved in addition to the task or problem to be solved. The task or problem creates the friction causing the change and stress, but it is the individual's ability to work through that change which is the key to emerging from an unhealthy crisis mode to one of acceptance and balancing of calculated risks. Quite simply, a practical approach to change starts with you.

Iterative changes are a familiar constant to library work. We are striving for incremental improvements and efficiencies that contribute to better systems, all in order to assess and improve what we already do. Examples of iterative change include bringing shelving time down by a percentage, establishing and maintaining qualitative benchmarks on effective instruction sessions, digitization standards, and the creation of new and improved discovery and fulfillment systems. There are several different methods and ideologies behind how to execute iterative change effectively and responsively, and librarians are trained to actively seek this type of change or improvement. We are wired this way. I mention this not to diminish or throw out iterative change as insignificant, but to call attention to the fact that libraries have always been in the business of change. We need to acknowledge this fact to ourselves and promote within and outside of our organizations that we are vastly different than what we used to be-and we are experts at doing this! Our libraries do not look like what they did in 1999 or even 2015-from a practical point of view, each of us can reflect upon all of the changes that we have participated in-willingly or not. Think about what went well, what didn't, what you could do over, and would you do it again? This thought process is all part of reflection, which is an important part of capping the change process at the end. Without that catharsis, it is quite stressful to keep doing this - yet we must.

The interesting detail about iterative change is that it promotes and enhances systems whose very natures are resistant to transformational change. It is important to work in a cycle of continuous improvement, but how does one recognize when the system itself should be 'blown up', 'destroyed', lays outside of our changing value systems, or heightens external threats? How does one recognize when a transformation is not only needed, but vital to survival? How does one identify the need for a transformative change and help bring a group 
of people through that transformation as well? These kinds of changes are infrequent and are giant leaps forward... hopefully. They are usually brought about by external factors such as a new building, a new leader, a budget crisis, or becoming more equitable and inclusive in all aspects of how we do business. These kinds of changes are substantive, are difficult, and require careful planning, processes, and change management principles in order to be successful. I am, once again, not glossing over this, but contend that libraries do this, talk about it at conferences, share through our literature, and, by sharing through our stories and experiences, help others through these transformational changes as well. This kind of change is complicated, and from a practical point of view, when done well, takes a long time and involves ongoing and empathetic communication, reminding, and reiteration of what the vision and end goal looks like. It happens successfully when all parties involved begin to think, 'not getting there is not an option,' a phase I have heard DeEtta Jones use for illustrating the mental mapping to successful change. Is this the secret to a practical approach? Perhaps, but I am also interested in practically dealing with another kind of change.

How do libraries and librarians deal with catastrophic change? I have been thinking about this quite a bit in the past six months-both in my own concerns with my current responsibilities, but also with larger trends that transcend libraries, higher education, scholarship or even humanity. I attended a panel presentation at the 2019 Charleston Conference which was discussing what it could look like if we were able to completely reimagine the relationship between libraries and scholarly publishing. One presenter began their portion by imagining what had to happen in order for this possible future to occur and concluded that only a catastrophe would accomplish this. This approach really struck a chord with me-are some of our systems, problems, and necessary changes so systemically rooted that only a catastrophe would enable significant change to occur? So rather than trying to ignore this concept, I have been thinking of how I would take a practical approach to catastrophic change. Do the tenets of Plan for the Worst, Hope for the Best, and Be Opportunistic still work? I would like to imagine how we approach catastrophes of expanding magnitudes when taken as threats to our livelihood, culture of privilege, or humanity.

We are slated to see a historic crash in university enrollment starting in 2025. While numbers may vary, data from $\mathrm{EAB}^{1}$ who provides research, services and technology to higher education leadership, demonstrates a drop in the number of 18 -year olds by $14 \%$ in 2029. I had thought, earlier in my career, that academia would face a crisis of online vs. in-person attainment of degrees. While online has certainly expanded significantly, it has not appeared to cause universities and colleges to shut down at the same levels that are predicted with this dramatic decrease in potential students starting five years from now. There has certainly been a trend, however, in the past 5 years, of smaller schools either merging or shutting down completely. So how have we, as professionals within higher education, dealt with this impending catastrophe? Practically speaking, the most demonstrable responses are the initiatives, strategies and planned activities of our deans, university librarians, provosts, and presidents for the next 5 to 10 years. They are all trying to keep the organization relevant and responsive-it just looks different depending on the type and focus of your particular institution. It is important for academic librarians to understand how the colleges and schools of their institution budget, evaluate, and plan for the programs and courses they offer. This effort is not just for the traditional purpose of collection development, but as a method for understanding, in a more proactive and engaged way, the shifts in how the business of the 
university is changing. Who are the university's competitors? What are their markets? What programs are expanding, and which may shrink? All this information is essential for success in this type of catastrophic change. EAB's research $\mathrm{arm}^{2}$ has published reports on the impact of foreign interference in higher education, demonstrating the impact of 'your grand challenge,' and even strategies on 'influencer marketing.' I would highly suggest placing their research reports in the same 'things to consider reading' category as some of the latest OCLC research reports.

In considering influential trends and environmental factors, I have been thinking about the impact of climate change. From a purely personal point of view, this has been focused on my family and its impact on my children and my own lifetime. It is especially difficult, because while I am wired to be an optimistic (yet practical!) person, it is hard to see anything positive within this particular kind of change. Rather than hoping that this won't happen, or somehow the world will get its act together, or that it was all bad science and isn't imminent, my thought is to flip the idea on its head and consider how we can truly plan for the assumption that climate change will force us to act radically different to preserve humanity and be ready to do it. How do we travel without traveling? How do we promote, create, and maintain sustainable library environments and services? How do libraries and library business partners help and promote long-term environmental stability? What does a pragmatic approach look like? There are already calls for reducing our carbon footprint through virtual conferences. However, we must lead and champion sustainability in our industry with a willingness to embrace radical change in order to ensure a hopeful future for us all. It is impressive what Greta Thunberg, the young Swedish climate change activist, was able to achieve by herself in the fall of 2019. We can draw inspiration from her and many other activists and organizations outside of the library landscape. I believe a practical approach to this catastrophe requires developing that strong voice and vision while building upon the foundational strength of academic libraries' collaborative and consortial partnerships.

Rather than viewing these threats as a dystopian nightmare, I would rather look at signs of planning and change agents that go beyond the transformative and may help us with the catastrophic. I view them as places from which to draw hope and inspiration. There are practical and inspirational examples to take our ability to be iterative and transformational to manage and mitigate the potential for catastrophe. One example I want to highlight is a significant announcement from the 2019 Charleston Conference. Brewster Kahle, of the Internet Archive, announced the purchase of Better World Books to create Better World Libraries. ${ }^{3}$ In the context of what he is trying to achieve, there is a big, radical, idea hiding in there. Namely, if the Internet Archive is essentially going down the pathway of digitizing 'all the books', and making them available to the world via controlled digital lending, how does this impact libraries and promote sustainability? What can we learn from them to inspire us to embark on the difficult path of changes that go beyond our comfort zones and position us to be better agents of practical change into the future? How does it promulgate information to the world, even if it may disadvantage the systems we are so comfortable and familiar with? How long before an ARL library goes all digital? How far away are we from virtual, instantaneous Interlibrary Loan? How long before over $90 \%$ of all our library users are virtual? When compared to the cost of an aircraft carrier, I would easily agree with Brewster's assertion that this is economically viable. I would also point out that it is probably "aircraft carrier level budget" kinds of projects in which we should embark for a better environmental future. And, in case you are 
curious, a Gerald R. Ford-class aircraft carrier costs just a shade under $\$ 13$ Billion and takes about 5-6 years to complete.

I have raised many questions and would like to spend some time discussing how to deal with this change and the necessary skillsets in order to be successful considering all of the possible futures. Contingency planning is a necessary method for dealing with all the possibilities of change. Have all the possibilities at hand and at your fingertips so that you can act when you are able. Set the table for change through discussion at all levels of your organization, encourage blue sky thinking, and engage in difficult, yet safe, conversations about what could be, even if it never happens. All of this is mental (and emotional). All of it! In looking at changes - both the flashy futurist versions and the ones that we do not realize, at the time, are as transformational as we believe-how do we mentally get to the point of internalizing that idea that not getting there is not an option? I have led six reorganizations over the past seven years, and can say with practical hands-on authority, that changes-both big and small-happen when the people involved are ready mentally. Changes from above, below or anywhere external to the people who undergo the change do not stick and do not succeed. Change comes from within, and most happens effectively and sustainably when the people involved are clamoring for it to happen. None of us appreciate or enjoy any kind of change in which we felt we were not involved in making it happen.

How can we imagine and launch a completely digitized / digital library when we still can't agree on loan periods, fines, or the prominence of a libguide from the library website? In working through change, it is extraordinarily important to understand the scope and the context. If passionate, albeit unwinnable, debates on library minutiae are blocking progress, then these kinds of conversations expose you and the organization to vulnerability. It is a critical skillset to realize that nothing is sacred, and anything can change. By transforming yourself and your approach to these conversations, you become the agent of change rather than have those changes dictated to you. Every library organization has its Achilles Heel about something - can you find a way to dismantle it and approach it differently? Are you too close and need someone else to look and point out the obvious? I think it is always healthy to question everything. Everything. It is not with the intention to get rid of everything, but at least to understand what is and is not important. It also gets people thinking. If done well, and in a safe manner, it allows for expansive thinking without assuming that everything is meaningless, pointless or without value. Finally, our library and university leaders should be obsessed with making sure there is a clear vision and a practical, relevant pathway for achieving it. What this looks like may be very different than personal values and beliefs and may change during one's employment at a given institution. If an institution's values and beliefs do not match yours, is this something you can live with? Our profession will have to wrestle with some dearly held beliefs in regard to privacy and the discovery and accessibility of knowledge in the next ten years - are you ready to have these conversations?

It is important to remember that while we may often feel that we are drowning in a sea of change, libraries have a long history of adaptation and reinvention along with occasional leaps of innovation and risk taking. Public libraries have seen a boon in the past decade as they have dealt intelligently and creatively with the catastrophe of a historic economic downturn, being one of the few places where communities could connect and receive responsive, relevant, and compassionate aid for many different user groups. That link between public perception-notably at the user level-and the public library's efficacy and programming are strong; perhaps 
stronger than the linkage seen at research universities between all the various communities of users and the library itself. We are juggling the various services, partnerships, innovations, and collections of our various constituents while also having to reinvent and reimagine our value proposition and taking on the mantle of preserving and increasing the discovery and access of the scholarly record - no small feat. It is being done in a constant state of decreasing budgets with increasing costs. In developing a new toolkit for being a practical agent of change, I propose the following core competencies for academic librarians. They include:

- The ability to rethink everything and revisit it every 6 months if necessary.

- Be the voice of your users and acknowledge their behaviors even if they are threatening to your current work responsibilities.

- Be influenced, but not overwhelmed, by the pace of change in the "real world."

- Lead and engage with empathy and emotional intelligence.

- Use your powers to move forward ethically and transform when you have the opportunity.

Changes happens every second of every day. Every change that you embark on happens one day at a time, one milestone at a time. Acknowledge and reflect upon what you have already achieved and understand that you have the strength to develop your core competencies for change so that our libraries and the institutions they serve are relevant and inspirational for generations to come. Good luck and remember that not getting there is not an option.

\section{Brad Warren \\ Associate Dean of Library Services University of Cincinnati Libraries \\ brad.warren@uc.edu}

\section{Notes}

1. Formerly the Educational Advisory Board, available online at https://eab.com [accessed 4 December 2019].

2. Educational Advisory Board, "Research and Insights," available online at https://eab.com/research-andinsights/ [accessed 4 December 2019].

3. "For the Love of Literacy-Better World Books and the Internet Archive Unite to Preserve Millions of Books," blog post November 6, 2019, available online at https://blog.betterworldbooks.com/2019/11/06/love-ofliteracy/ [accessed 4 December 2019]. 